\title{
The diet of three medieval individuals from Caravate (Varese, Italy). Combined results of ICP-MS analysis of trace elements and phytolith analysis conducted on their dental calculus
}

\author{
Agnese Maria Barbara Lazzati ${ }^{A}$, LuCa LeVrini ${ }^{A}$, LaUra Rampazzi ${ }^{\mathrm{B}}$, Carlo Dossi ${ }^{\mathrm{C}}$, Lanfredo

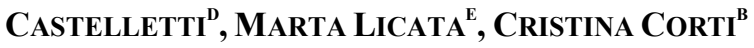

\footnotetext{
a Dipartimento di Scienze Chirurgiche e Morfologiche, Università degli Studi dell’Insubria, Via Guicciardini 9, 21100 Varese, Italy

${ }^{\mathrm{b}}$ Dipartimento di Scienza e Alta Tecnologia, Università degli Studi dell'Insubria, via Valleggio 11, 22100 Como, Italy ${ }^{\mathrm{c}}$ Dipartimento di Scienze Teoriche e Applicate, Università degli Studi dell'Insubria, Via J.H. Dunant 3, 21100 Varese, Italy

${ }^{\mathrm{d}}$ Laboratorio di Archeobiologia, Musei Civici, Piazza Medaglie d'Oro 1, 22100 Como, Italy

e Dipartimento di Biotecnologie e Scienze della Vita, Università degli Studi dell'Insubria, Via J.H. Dunant 3, 21100 Varese, Italy

*Corresponding author

Cristina Corti, email address: cristina.corti@uninsubria.it
}

\section{RUNNING TITLE}

Dental calculus and medieval diet

\begin{abstract}
Teeth are in close contact with foodstuffs: phenomena such as caries and wear of the crowns are precious keys to gather information on diet and cooking techniques.

Phytoliths are granules of hydrated amorphous silica, which are deposited in the oral cavity while chewing fruit and vegetables and incorporated into dental calculus during its formation. In diet investigation, different plants may therefore be related to specific phytolith shapes.

Analysis of chemical trace elements, incorporated in dental calculus from ingested food and replacing small percentages of calcium in normal processes of resorption and redeposition, can further enrich the research on ancient diet.

The aim of our work was to set up an analytical protocol, focalised on phytoliths and the inorganic elemental composition of dental calculus, on samples coming from medieval skeletons excavated in Caravate (Varese, Italy). The ICP-MS analytical technique proved to be particularly suitable for such studies.

The results suggested a diet based both on the consumption of carbohydrates (Dicotyledons, Monocotyledons such as the Poaceae, also known as Gramineae, and Coniferae) and on proteins, mostly derived from fish.
\end{abstract}

Keywords: Medieval diet; dental calculus; phytolith; optical microscopy; SEM-EDX; trace elements; ICP-MS 


\section{INTRODUCTION}

Paleodiet is defined as the field of study of anthropology that, through the examination of a variety of indicators (skeleton and teeth, dental calculus, hair, nails, gall stones, calcified tumours, soft tissue residuals, etc.), collectable from human remains found in archaeological sites, attempts to reconstruct the diet of a specific past population.

Teeth are in close contact with foodstuff that is introduced with the diet. Food and oral health are thus two aspects that are closely related. Food has a direct role on the balance of oral flora, which, if altered, may lead to phenomena such as caries, formation of dental calculus, and periodontal disease. The dental calculus, or tartar, is a hard concretion, which is formed by calcification of plaque. It is located on the surfaces of the teeth, on both (buccal and lingual) sides of the teeth, in a supra- or sub-gingival position.

The presence of pathogenic bacteria and tartar in the oral cavity can lead to cavitary lesions, of varying depth, or loss of the element itself intra vitam, due to resorption of the supporting tissues such as bone and periodontal ligament. Bacteria can easily remain trapped in the crystalline matrix, so dental calculus can be considered as a precious source of preserved human microbiota (Adler et al., 2013). Genetic analyses on ancient bacterial DNA can be used to trace dietary changes, health and movements of past populations. All these elements are important in understanding the type of diet, the processing of food and its cooking, as well as the general state of health of the individual.

Food can also affect the degree of wear of the tooth crowns. Therefore, in addition to a macroscopic study, a micro-configuration analysis of wear allows us to understand the type of diet (hard or soft) and whether based mainly on vegetables, grains or meat (Lalueza et al., 1994; Ungar et al., 2006).

Dental calculus is constituted by both organic and inorganic components. The organic fraction is made of proteins, carbohydrates and lipids and amounts to about $12 \%$ of the total weight; the remaining $88 \%$ has an inorganic nature, and it is made of calcium phosphate, traces of magnesium phosphate and other elements. The composition is very similar to that of bones and teeth (Henry et al., 2011; Lieverse, 1999; Lindhe et al., 2008; Perez et al., 2004). Its mechanism of formation is still not fully understood, but it surely involves the deposition of calcium and phosphate from the saliva and gingival fluids into the matrix of biofilm that constitutes oral plaque (Hayashizaki et al., 2008). Many authors linked the formation of calculus with the amount of carbohydrates consumed, whilst others showed a connection with the ingestion of proteins. The controversy is still open (Arnay-de-la-Rosa et al., 2009). For what concerns the time frame of calculus accumulation, the rate of deposition depends on a number of aspects, such as genetic predisposition, diet and oral healthcare (Mickleburgh and Pagán-Jiménez, 2012).

Dental calculus is mineralized, so it commonly survives in archaeological human remains, in the form of a hard deposit on teeth (Lieverse, 1999). Different calcium phosphates can be found, partly depending on the degree of 'maturation' of the pathological concretion. In particular, hydroxyapatite, dicalcium phosphate dihydrate, octacalcium phosphate and whitlockite are generally observed (Hayashizaki et al., 2008; Perez et al., 2004). The crystals of phosphates can also exchange ions with the oral fluids and adsorb organic compounds (Abraham et al., 2005; Perez et al., 2004). Divalent cations can enter the lattice and replace calcium and many different anions, such as silicate, can substitute phosphates. 
Whilst the major elements in dental calculus are $\mathrm{Ca}, \mathrm{P}$ and $\mathrm{Mg}$, its minor components are very variable and not still extensively studied (Hayashizaki et al., 2008; Molokhia and Nixon, 1984; Perez et al., 2004).

Some articles about chemical analysis of calculus can be found in the literature, generally focused on mineralogical phases of modern individuals, but sometimes also on elemental composition and on ancient samples. It is reported, for example, the use of X-ray diffraction (XRD) (Hayashizaki et al., 2008), Fourier transform infrared spectroscopy (FTIR) (Hayashizaki et al., 2008), fluorescent X-ray spectroscopy (XRF) (Hayashizaki et al., 2008) and synchrotron radiation analysis by X-ray fluorescence (SRXRF) (Abraham et al., 2005; Perez et al., 2004; Sanchez et al., 2000). Data were also collected using scanning electron microscopy associated with X-ray spectrometry (SEM-EDX) (Charlier et al., 2010; Hardy et al., 2012), gas chromatographymass spectrometry (Hardy et al., 2012) and instrumental neutron activation analysis (INAA) (Molokhia and Nixon, 1984).

As previously ascertained, dental calculus can be a source of information about diet, through the analysis of chemical trace elements. In recent years, considerable progress has been made in dietary studies, thanks to the use of instruments such as Inductively Coupled Plasma Mass Spectrometry (ICP-MS), by which it is possible to perform a fast and precise analysis of trace elements contained in various types of samples, including teeth and bones. The evaluation of concentration and the isotopic abundances of certain elements to obtain information about past populations is now possible (Budd et al., 1998; Busetto et al., 2008; Corti et al., 2013; Djingova et al., 2004; Klepinger, 1984; Lambert et al., 1979; Schutkowski et al., 1999; Simonetti et al., 2008; Szostek et al., 2003; Szostek and Głąb, 2001; Tomczyk et al., 2013; Webb et al., 2005).

The most important elements used in palaeonutritional studies are strontium and zinc. Strontium is contained in foods such as cereals and vegetables and can provide an indication of the consumption of carbohydrates, while zinc comes from foods such as red meat, fish, egg yolk, dairy products, vegetables and seafood, and indicates the consumption of proteins (Beck, 1985; Busetto et al., 2008; Janos et al., 2011; Lambert et al., 1984; Rheingold et al., 1983). Lambert et al. reported values of strontium in bones in the range 400-500ppm for herbivores, 150-400ppm for omnivores and 100-300ppm for carnivores; they also reported low concentrations of zinc in herbivorous animals (90-150ppm), intermediate for omnivores (120-220ppm) and higher for carnivores (175-250ppm) (Lambert et al., 1984). The reason why the amount of these elements in bones can change is linked to the element's capability to replace small percentages of calcium in normal processes of resorption and redeposition, which is typical of bone tissue and depends on the type of diet. Lead is another important element in this analysis, due to the fact that its value increases in the presence of post-mortem contamination, so it can be used as a marker of the 'good preservation' of skeletal samples. Finally, isotopic analysis of carbon and nitrogen has been applied to tooth and bone collagen to indicate the source of certain vegetable foods and to determine the prevalence of a vegetarian or carnivorous diet.

Similar to bones, dental calculus (if not removed) is in a continuous state of formation and remodelling and can potentially record elemental information during life, whilst enamel tends to be more resistant to the incorporation of elements, due to its peculiar stability after formation (Budd et al., 1998; Webb et al., 2005). In agreement with the approach of Scott and Poulson (2012) dental calculus can be a suitable material to investigate paleodiet in such cases when museum curators do not authorize the use of archaeological teeth and bones. Dental calculus is not an inherent original part of the skeleton, but just an 'add-on' so its sampling and analysis can be considered as a 'non-destructive' technique. Scott and Poulson (2012) also found encouraging 
clues to support the link between diet and dental calculus stable isotope composition, which were a lead for our study.

Moreover, further features of the paleodiet can be revealed by the analysis of phytoliths (Blatt et al., 2011; Buchet et al., 2001; Dudgeon and Tromp, 2012; Henry et al., 2011; Henry and Pipemo, 2008; Lalueza et al., 1996; Menendez et al., 2009; Piperno, 2006; Power et al., 2014; Wesolowski et al., 2010). Phytoliths are granules of amorphous silica (95\%), water (4\%) and trace elements (1\%), of variable size between 5 and $200 \mu \mathrm{m}$, produced by plants. They are deposited in the oral cavity while chewing fruit and vegetables and then incorporated into dental calculus during its formation. Their morphologies are specific to particular plants, therefore, from the recovery of an isolated phytolith, it is possible to recognize taxa of higher rank, such as families, tribes or subfamilies of the plant that formed it, thus obtaining information about the diet. In particular, the phytoliths research and identification point to the food eaten in the last times before death, are nondestructive, cheap and give information on specific plants (Boyadjian et al., 2007). Hardy et al. (Hardy et al., 2012) considered both phytoliths and organic chemical compounds found in dental calculus of a Neanderthal population. Carbohydrate markers, fatty acid esters and combustion markers were directly linked to the ingested food and to the method of cooking. A similar approach was used by Buckley et al. (Buckley et al., 2014).

Therefore, the aim of our work was to set up an analytical protocol, for the investigation of phytoliths and the elemental composition of dental calculus. To the best of our knowledge, this is the first use of ICP-MS for trace element analysis on dental calculus. The research was conducted on samples coming from medieval skeletons that were excavated in Caravate (Varese, Italy).

\section{ARCHAEOLOGICAL CONTEXT}

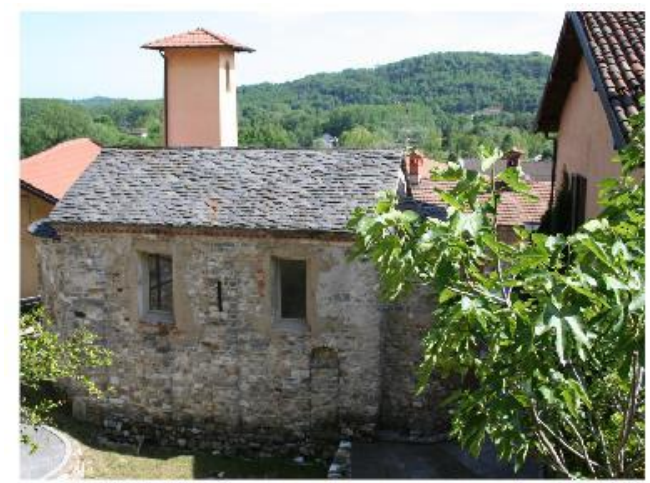

(A)

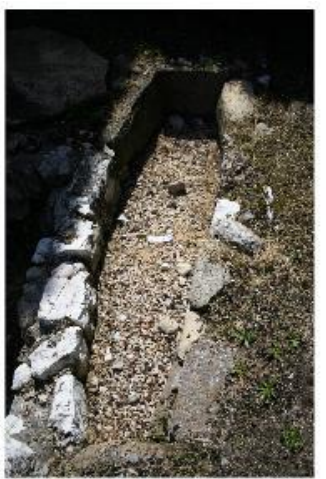

(B)

Figure 1 - (A) -The Church of St. Augustine in Caravate, Varese, Italy; (B) - The tomb of individual Tb7 US 118

This study was conducted by examining skeletons that were buried adjacent to the church of St. Augustine in Caravate (Figure 1), an Italian town of 2632 inhabitants near Varese, Lombardy.

The origin of the site name 'Caravate' is uncertain: it is thought to derive either from the Celtic name of person 'Carevus', or from pre-Latin carabus or caravos, which derives from karra, i.e. stone (or from caravum, heap of stones). It is also possible that this name derives from the ancient Caravè, a place where hemp was macerated (Armocida and Pozzi, 2004). The latter hypothesis is supported by some findings of fossils, which suggest that 
the area surrounding this town was originally a large swamp in which hemp was placed to soak. The history of this town extends from the Celtic domination up to the Roman. The reason for so much attention on the site by so many people probably lies on its strategic position, which made it easy to defend. Although Christianity was practiced in Caravate since the 4th century $\mathrm{AD}$, it was not until the subsequent conquest of the village by the Lombards that the building of churches was promoted, like the one dedicated to St. Augustine.

This church was built between the 11th and 12th centuries AD and was later renovated several times. During some recent restoration work a subsidence of the land suggested the presence of a cemetery on the north side of the building. Since then an archaeological survey was carried out in four phases, from August-October 2002 and again in January-March 2003 under the direction of Dr. M. A. Binaghi. After a simple clean up of the site and the levelling of the land, the first two burials came to light in a tomb structured and covered with a stone slab. These burials were aligned with each other and oriented along the east-west axis in the Romanesque tradition, about $2 \mathrm{~m}$ away from the wall of the church. After removing the cover stone, two skeletons of adult individuals in good condition were found. A third burial was revealed, leaning against the north wall of the church. At the time of the discovery, the tomb, whose small size suggested it was built for a child, was already emptied and its structure overturned. A fourth burial was later found but was full of debris and, unlike the others, the tomb was built of squared limestone blocks but did not have any coverage.

The clean up of the entire area north of the church of St. Augustine was then completed and other graves and niches were discovered, aligned along the east-west axis, but built in different times.

Among all the tombs discovered, those against the wall of the church were the oldest, whilst those farther away from the church were more recent. The different periods of construction were also evident based on the fact that the oldest tombs were well structured, whilst the subsequent ones showed the re-use of previous tombs. This was confirmed by the discovery of a skeleton of an adult in a tomb originally belonging to a child: to be able to push the body within the available space, the body was placed on its side and several bones in the neck, arms and legs were broken. To expand the small tomb as much as possible the closure to the east was also torn down. Besides the re-use of previously existing graves, materials from the tombs were later also recycled to satisfy the demand of a growing population. This was easily visible in burial number 5, which was partially superimposed on the oldest loculus and some of the original tomb components were used.

At the end of the survey in the areas north and east of the site, ten tombs had been found, seven still sealed and three emptied. The seven skeletons were in good condition and belonged both to adults and to adolescents. In addition to these, a square stone bearing an inscription was found and is currently under study.

\section{MATERIALS AND METHODS}

\section{Skeletons and samples of dental calculus}

A total of seven samples were collected from three skeletons, named respectively Tb6 US 115, Tb7 US 118 and Tb9 US 129.

They were the only ones available because the rest had already been cleaned, catalogued and studied by archaeologists. All the dental calculus found on the teeth of these three skeletons was collected, subdividing the various samples depending on the tooth and the surface where calculus was collected. Five samples were taken 
from the lingual surface of the teeth, which faces the inside of the oral cavity and the tongue, and two from the buccal surface, which faces the lips.

Two of the samples were taken from the first skeleton Tb6 US 115: one from the lingual surface of the element 3.4 (permanent mandibular left first premolar) and one from the lingual surface of the element 3.5 (permanent mandibular left second premolar).

From the second skeleton, one sample was collected from the lingual surface of the element 4.6 (permanent mandibular right first molar).

Eventually four samples were collected from the third skeleton: one from the buccal surface of the element 3.3 (permanent mandibular left canine), one from the buccal surface of the element 4.4 (permanent mandibular right first premolar), one from the lingual surface of the element 4.6 (permanent first mandibular right molar) and one from the lingual surface of the element 4.7 (permanent mandibular right second molar).

Collected samples are summarised in Table 1. Also included in Table 1 is a summary of the analytical techniques used depending on the amount of available calculus.

\begin{tabular}{|c|c|c|}
\hline \multirow{2}{*}{ individual } & $\begin{array}{c}\text { dental element and surface of } \\
\text { provenance }\end{array}$ & analysis \\
\hline \multirow{2}{*}{ Tb6 US 115 } & 3.4 (lingual) & optical microscopy \\
\cline { 2 - 3 } & 3.5 (lingual) & optical microscopy, SEM-EDX, ICP-MS \\
\hline Tb7 US 118 & 4.6 (lingual) & optical microscopy, ICP-MS \\
\hline \multirow{3}{*}{ Tb9 US 129 } & 3.3 (buccal) & optical microscopy, SEM-EDX \\
\cline { 2 - 3 } & 4.4 (buccal) & optical microscopy, SEM-EDX \\
\cline { 2 - 3 } & 4.6 (lingual) & optical microscopy, SEM-EDX \\
\cline { 2 - 3 } & 4.7 (lingual) & optical microscopy, SEM-EDX \\
\hline
\end{tabular}

Table 1 - List of the seven samples collected and analysed, with the techniques applied

\section{Reagents}

Ultrapure water (18M $\Omega$ resistivity, $<5 \mathrm{ppb}$ TOC) from a Milli-Q Gradient A10 system (Millipore) was used throughout the analytical procedure. Ultrapure $\mathrm{HCl}$ and $\mathrm{HNO}_{3}$ were produced by sub-boiling distillation in a quartz apparatus (DuoPUR, Milestone). Glacial $\mathrm{CH}_{3} \mathrm{COOH}$ (Suprapur grade from Merck) was used to clean the samples. A 10mg/l multi-element standard solution (Merck Certipur ICP multi-element standard solution XXI) was used to prepare standard solutions at lower concentrations. Another solution (Multi-element Tune A solution, Analytika) was used to optimise the ICP-MS settings.

All the manipulations were performed in a Class 100 laminar-flow hood to prevent external contamination. Low-density polyethylene (LDPE) sample and reagent bottles and vials were washed and stored in $2 \% \mathrm{HNO}_{3}$ and rinsed with ultrapure water before use. 


\section{Sampling and sample preparation}

A modified version of the protocol of C. Lalueza was followed (Lalueza et al., 1996). The teeth were cleaned with a soft toothbrush and abundant deionised water in order to eliminate possible soil residues. Small fragments of dental calculus were then removed with a sterile curette and kept in clean LDPE vials.

\section{Optical microscopy and SEM-EDX for phytolith analysis}

The samples were soaked in a solution of $20 \% \mathrm{HCl}$ for 6-8 hours and then disintegrated with the aid of ultrasonic waves. The residuals later underwent three series of washings with ultrapure MilliQ water, centrifugation and removal of the liquid part of the samples. This would eliminate most of the chlorides, which otherwise would have had the tendency to crystallise.

The samples were then transferred into plastic coverslips and left to dry in a stove overnight at $70^{\circ} \mathrm{C}$. Once dried, they were observed through optical and electronic microscopes.

An optical Nikon Eclipse E600 microscope was used, equipped with a digital acquisition system (Nikon Digital Sight D5-U1) and controller software (Nikon NIS-Elements F).

A field emission gun scanning electron microscope (FEG-SEM) FEI XL-30 was used along with an EverhartThornley detector for secondary electrons (SE), annular detector for backscattered electrons (BSE) and X-ray spectrometer (EDAX) detector EDAX Sirion 200/400 with controller software EDAX Genesis 5.21. Prior to the analysis, samples were thinly coated with gold or carbon.

Elemental analysis of the samples was performed with EDAX and each chemical element of interest was matched to a different colour in order to obtain colour maps useful for displaying the phytoliths. When a silica particle was found, it was enlarged, photographed and its morphology was observed. Phytoliths were then identified with the help of a collection of recent specimens existing at the 'Laboratorio di Archeobiologia' in Como.

\section{ICP-MS for trace elements analysis}

Samples were taken with PTFE-coated stainless steel tweezers in order to prevent contamination, and then rinsed with a $5 \% \mathrm{CH}_{3} \mathrm{COOH}$ solution to eliminate the superficial layers that could have been contaminated by soil during burial or by metallic tools during excavation or sampling (Bentley et al., 2003; Price et al., 2000). Samples were then rinsed with ultrapure water and desiccated in a drying oven at $40^{\circ} \mathrm{C}$ for 3 hours.

Samples were weighed (Tb6 US $1158.17 \mathrm{mg}$; Tb7 US 118 9.13mg) and placed in clean LDPE bottles: then 1ml of ultrapure $\mathrm{HNO}_{3} 67.4 \%$ was added. Bottles were closed and placed in an ultrasonic bath for 30s to enhance the dissolution. After this step, the resulting samples were completely disaggregated.

The solutions obtained were then gravimetrically diluted to $3 \mathrm{~g}$ with ultrapure water and stored at $4^{\circ} \mathrm{C}$ until analysis.

The solutions were then diluted at 1:200 and at 1:15 with a solution of $2 \% \mathrm{HNO}_{3}$ in ultrapure water just before the analysis to assure that the analytes were within the calibration range. Two final solutions were obtained for every sample.

A procedural blank solution was prepared with ultrapure $67.4 \% \mathrm{HNO}_{3}$ and ultrapure water. 
An ICP-MS (Thermo Elemental X-Series II), equipped with a Cetac ASX-260 autosampler and a concentric nebuliser was used. Optimisation of the instrument settings was performed daily with a $10 \mu \mathrm{g} / 1$ multi-standard solution, as recommended by the manufacturer.

The optimised parameters used for analysis are: argon plasma gas flow $131 / \mathrm{min}$; auxiliary gas flow $0.81 / \mathrm{min}$; nebuliser gas flow 0.901/min; ICP-RF power 1400W; dwell time 10,000ms; acquisition mode peak jumping; sample uptake rate $0.4 \mathrm{ml} / \mathrm{min}$; sweeps per reading 80 ; sampling depth 150 arbitrary units; instrumental repetitions 5 runs.

Multistandard solutions at $0.05,0.1,0.5,1,5,10,20$ and $50 \mu \mathrm{g} / \mathrm{l}$ in $2 \% \mathrm{HNO}_{3}$ were prepared. The following isotopes were chosen: ${ }^{7} \mathrm{Li},{ }^{9} \mathrm{Be},{ }^{23} \mathrm{Na},{ }^{25} \mathrm{Mg},{ }^{27} \mathrm{Al},{ }^{39} \mathrm{~K},{ }^{51} \mathrm{~V},{ }^{52} \mathrm{Cr},{ }^{55} \mathrm{Mn},{ }^{59} \mathrm{Co},{ }^{60} \mathrm{Ni},{ }^{65} \mathrm{Cu},{ }^{66} \mathrm{Zn},{ }^{69} \mathrm{Ga},{ }^{75} \mathrm{As},{ }^{85} \mathrm{Rb}$, ${ }^{88} \mathrm{Sr},{ }^{111} \mathrm{Cd},{ }^{137} \mathrm{Ba},{ }^{208} \mathrm{~Pb},{ }^{209} \mathrm{Bi},{ }^{238} \mathrm{U}$.

A procedural blank was also analysed.

\section{RESULTS AND DISCUSSION}

\section{Phytolith analysis by Optical Microscopy and SEM-EDX}

Two samples were taken: one from the lingual or inner surface of the mandibular second right premolar (element 3.5) of the skeleton Tb6 US 115 and another from the buccal or outer surface of the mandibular right canine (element 3.3) of the skeleton Tb9 US 129. Both samples were analysed with EDAX.

The results of this analysis showed that the elemental spectra of these two samples were similar: all spectra were dominated by a peak of chlorine, caused by the use of hydrochloric acid to dissolve the calculus, and in all of them there were peaks of other elements such as potassium, sulphur, phosphorus, carbon, nitrogen and oxygen, whose origin could be either organic or inorganic. Also, aluminum and silicon were detected, whose origin is definitely exogenous. Due to the high content of silicon in the samples, it was possible to hypothesize the presence of phytoliths, which consist predominantly of this element.

For what concerns the research of phytoliths, it must be noted that their probability to remain trapped inside the oral cavity during mastication of fruit and vegetables is rather poor and that the same calculus formation takes place in relatively short times (days or weeks).

Thanks to EDAX it was possible to create maps associating specific chemical elements to different colours: red has been assigned to carbon, green to aluminium and blue to silicon.

The maps created with EDAX made it possible to identify the particles containing silicon, because they were blue: once photographed, their morphology was studied by means of optical and electronic microscopy. An example of a map can be observed in Figure 2.

The observation of the samples with optical and electronic microscopy led us to identify some phytoliths from the Poaceae family (also named Gramineae) (Figure 3), with elongated, polyhedral or thorn-like shapes. Phytoliths are present in the cells of the chaff, of the rachis of the ear, and in the stem and leaves. When using naked grain cereals or those that have been hulled but thoroughly cleansed from their glumes (husked), there is little chance that the phytoliths would be introduced with food in the mouth. 


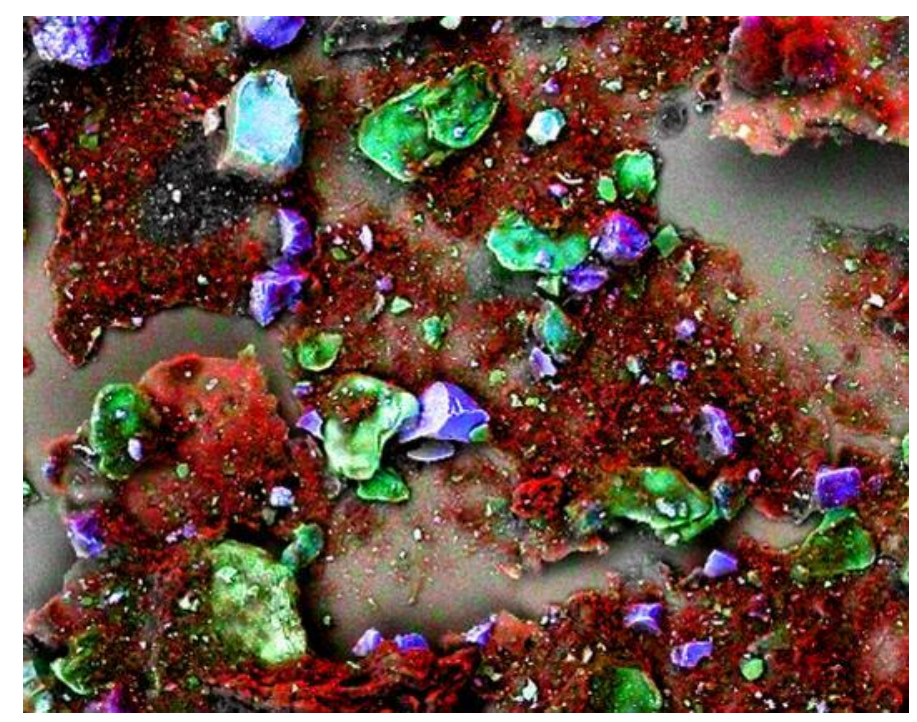

Figure 2 - EDAX mapping of the sample 3.5 L Tb6 US 115

The Gramineae phytoliths appear to be scarce and difficult to identify due to the lack of characteristic features for identification. Most of these phytoliths were fragmented and occurred very sporadically.

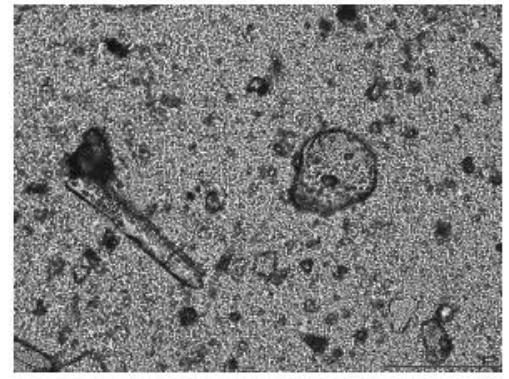

(A)

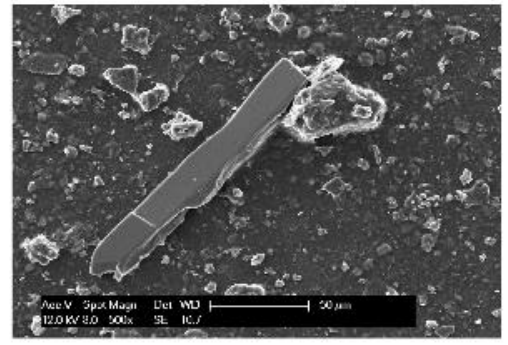

(B)

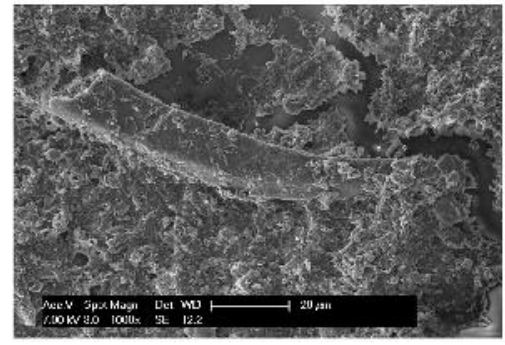

(C)

Figure 3 - (A) - Trapezoidal winding phytolith (left) of the family of Poaceae, sample 4.6L Tb7 US 118; (B) - Fragmented long-shaped phytolith, width $17 \mu \mathrm{m}$, sample 4.6L Tb7 US 118; (C) - Trichome or thorn, elongated and hollow, measuring $15 \mu \mathrm{m}$ in diameter just above the base and probably forming part of a remain of cereals, sample 4.6L Tb9 US 129

What is preserved in the dental calculus is often not part of the actual food but is instead sporadically deposited from an external source, or perhaps through food preparation and manipulation before, during and after cooking. For example, it is in theory possible to find fragments of wood from wooden containers or cutlery, chips of charcoal from the fireplace (micro-charcoals), inorganic substances such as mineral silica, or tectosilicates from a totally exogenous source, among other things (Buckley et al., 2014; Mickleburgh and Pagán-Jiménez, 2012).

Some phytoliths from wood of the class of Dicotyledons and perhaps Conifers (e.g. for the symbolism of conifers Rabanus Maurus (Petrocchi, 1982)) were also found: some smooth rods, some polyhedral fragments (Figure 4) and one small probable fibre. Obviously, these are part of unintentionally ingested elements, received with food or directly into the mouth by other means. 


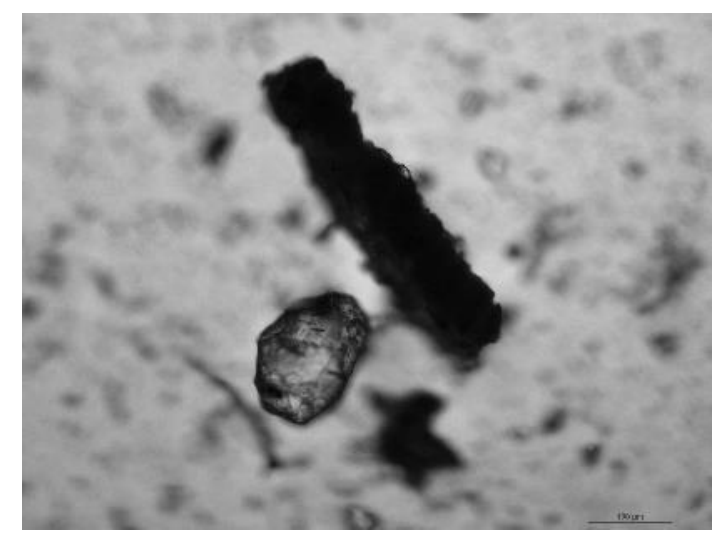

Figure 4 - Probable polyhedral phytolith from charred wood, sample 3.3V TB9 US 129

The examination of the samples with optical microscopy showed several dark charcoal-like fragments, which were identified as burned (Parr, 2006) or carbon coated phytoliths. Other fragments, like micro-charcoals derived from sparks raised during the combustion in the hearth, were included in the cooking vessel and consequently found among the samples.

Some fibres were also found in the samples: some ribbon-like plates, other cylindrical elements with or without chippings as well as ribbon-like (helicoidal) twisted fibres.

Some other particles were found in the dental calculus samples, as can be seen in Figure 5.

A large number of inorganic components, including micas, quartzes and flint, which are likely to derive from the soil, were also found. These components could be trapped in the calculus because of the cleaning of vegetables or from containers. These components could also be the result of a residue from the milling of cereals with millstones made of sandstone, conglomerates, breccias and crystalline rocks such as granite (e.g. Figure 5a). The nature of these inorganic components was consistent with the geology of the area of Caravate.

A fragmented rectangular perforated plate $(1.7 \mu \mathrm{m} \times 1.3 \mu \mathrm{m})$ with a double row of 4 holes (diameter $0.3 \mu \mathrm{m}$ ) arranged orthogonally was found in sample 3.4L Tb6 US 115 (Figure 5b). A similar object can be found both in Dicotyledons (for example Ericaceae) and in Conifers. However, given the small size of the frustule, similar structures could also be present in the shrine of diatoms, either Centrales (marine) or Pinnales (freshwater).

The observation by optical microscope in transmitted light of the sample 3.5L Tb6 US 115 highlighted objects of ellipsoidal-round shape, measuring between 40 and $60 \mu \mathrm{m}$ (Figure $5 \mathrm{c}$ ). Some other smaller round-oval bodies (about $10 \mu \mathrm{m}$ ) with a sort of hilus characteristic of starch granules were also found but not further investigated. This study was conducted on pictures previously taken, so a deeper investigation was not possible.

A not well-defined rounded body was found in the sample 4.6L Tb9 US 129, with traces of small spines on the surface and a diameter of $45 \mu \mathrm{m}$ (Figure $5 \mathrm{~d}$ ). It is not a pollen grain but it may be a cystolith (i.e. a crystal of calcium carbonate produced by particular plant cells called lithocites), probably an urticals tribe cystolith. Urtica sp. is an edible plant and was used as 'spinach' and for soups (Maurizio, 1932). 

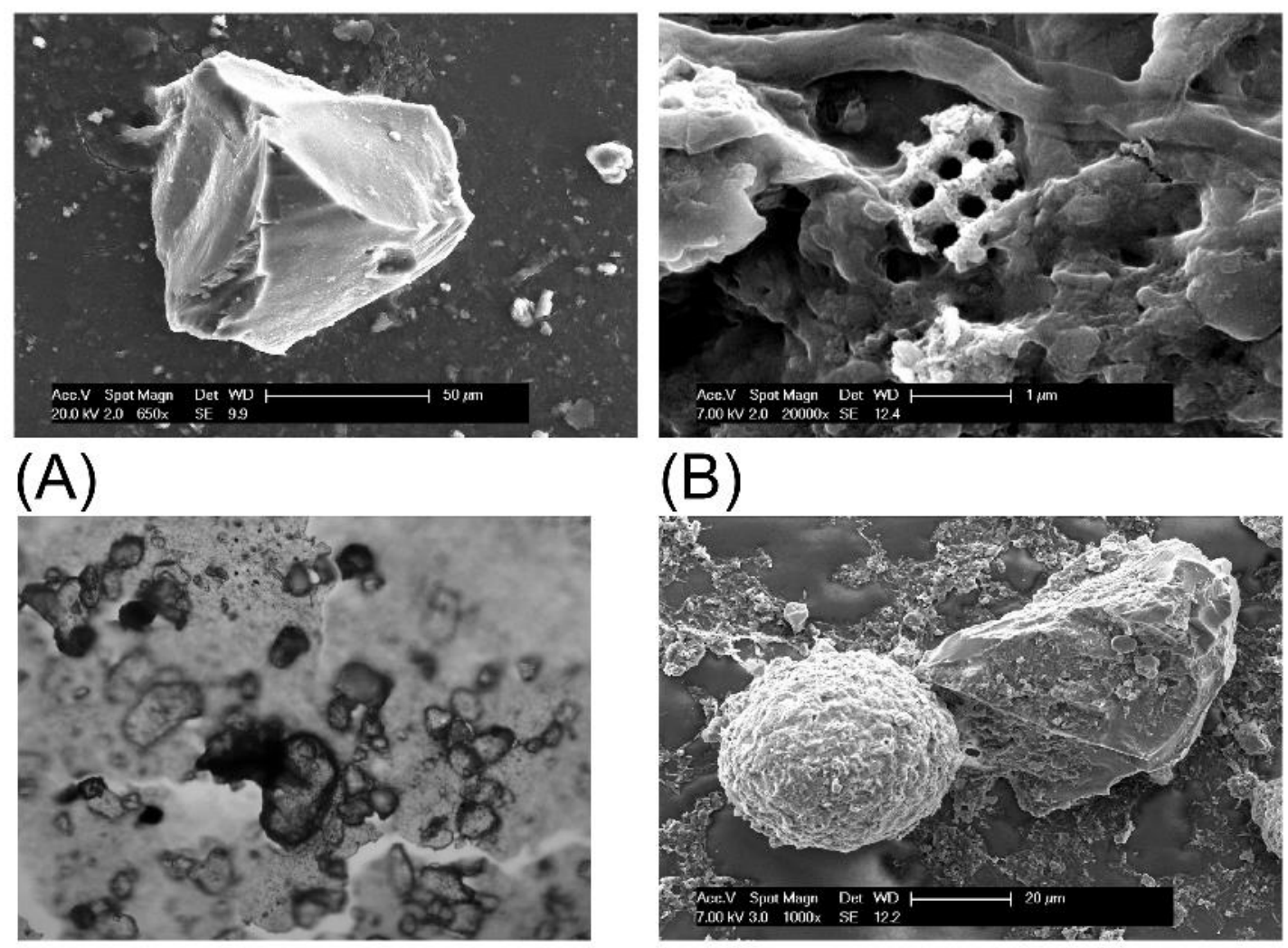

(C)

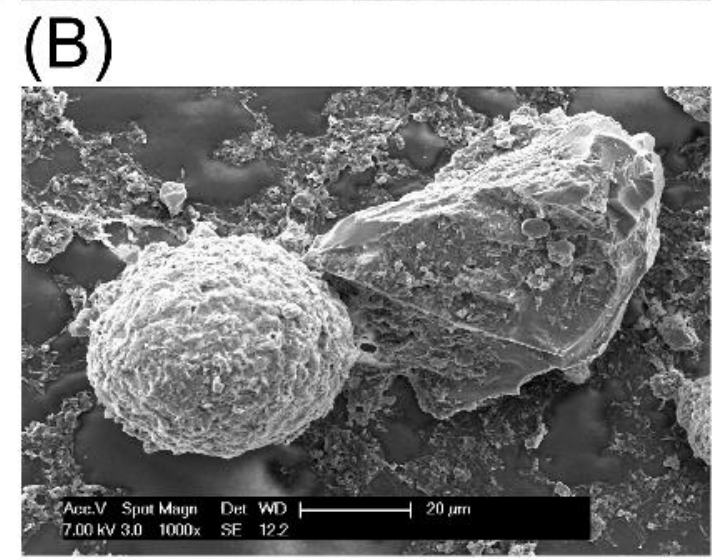

(D)

Figure 5 - (A) - Fragment with conchoidal fracture that appears to derive from non-crystalline silicon dioxide (flintstone), sample 3.3V Tb9 US 129 - (B) - Fragmented rectangular perforated plate, $1.3 \mu \mathrm{m}$ with a double row of 4 holes (diameter $0.3 \mu \mathrm{m}$ ) arranged orthogonally,

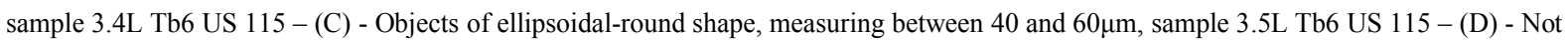
well definable rounded body with traces of small spines on the surface and diameter of $45 \mu \mathrm{m}$, sample 4.6L Tb9 US 129

\section{ICP-MS trace element analysis}

The procedure set up for ICP-MS analysis required a sample to be dissolved, amounting to at least $5 \mathrm{mg}$. Only the Tb6 US 115 and Tb7 US 118 samples satisfied this requirement as enough sample was saved after the treatment for the research of phytoliths.

The analytical results are summarised in Table 2 where the concentrations of all the analysed elements are reported. In the following discussion only the elements which are relevant from the dietary point of view will be considered.

Due to the lack of reports in the literature about using ICP-MS on fragments of dental calculus, it was decided to follow a sample pre-treatment similar to the one used on tooth enamel and bone, because they are all constituted predominantly of calcium compounds, independently from their mechanism of formation (Lindhe et al., 2008).

Both samples (Tb6 US 115 and Tb7 US 118) gave similar results in terms of elemental composition. Their concentrations are comparable to those that would be expected from an analysis of dental enamel or dental calculus. The two biological materials have different mechanisms of incorporation of trace elements, the first one is biological, whilst the second is a physical entrapment and can be seen as a stochastic process. An approach similar to Hardy et al. (2012), who analysed organic chemical compounds found in dental calculi and directly linked them to the ingested food and to the method of cooking, was followed. Moreover, in the lack of 
an extensive literature about elemental composition of dental calculus, the same approach of Scott and Poulson was followed and the measured values were mostly compared with those related to teeth (Scott and Poulson, 2012).

\begin{tabular}{|l|l|l|l|l|}
\hline & \multicolumn{2}{|l}{ Tb6 US 115 3.5 lingual } & \multicolumn{2}{l|}{ Tb7 US 118 4.6 lingual } \\
\cline { 2 - 5 } & $\begin{array}{l}\text { mean } \\
(\mathrm{mg} / \mathrm{kg})\end{array}$ & $\begin{array}{l}\text { std dev } \\
(\mathrm{mg} / \mathrm{kg})\end{array}$ & $\begin{array}{l}\text { mean } \\
(\mathrm{mg} / \mathrm{kg})\end{array}$ & $\begin{array}{l}\text { std dev } \\
(\mathrm{mg} / \mathrm{kg})\end{array}$ \\
\hline $\mathrm{Li}$ & 0.67 & 0.01 & 0.33 & 0.01 \\
\hline $\mathrm{Be}$ & 0.14 & 0.01 & 0.06 & 0.01 \\
\hline $\mathrm{Na}$ & 3877.11 & 48.96 & 3700.95 & 55.89 \\
\hline $\mathrm{Mg}$ & 1851.86 & 14.21 & 1428.73 & 25.87 \\
\hline $\mathrm{Al}$ & 663.73 & 4.50 & 220.06 & 3.19 \\
\hline $\mathrm{K}$ & 364.04 & 19.09 & 539.56 & 25.02 \\
\hline $\mathrm{V}$ & 5.62 & 0.10 & 4.39 & 0.11 \\
\hline $\mathrm{Cr}$ & 3.54 & 0.04 & 7.76 & 0.29 \\
\hline $\mathrm{Mn}$ & 334.26 & 2.52 & 188.18 & 2.95 \\
\hline $\mathrm{Co}$ & 0.88 & 0.01 & 0.55 & 0.02 \\
\hline $\mathrm{Ni}$ & 12.29 & 0.21 & 12.08 & 0.63 \\
\hline $\mathrm{Cu}$ & 34.60 & 0.36 & 19.28 & 0.50 \\
\hline $\mathrm{Zn}$ & 867.86 & 8.60 & 456.15 & 2.83 \\
\hline $\mathrm{Ga}$ & 4.06 & 0.04 & 3.44 & 0.14 \\
\hline $\mathrm{As}$ & 0.59 & 0.09 & 0.36 & 0.08 \\
\hline $\mathrm{Rb}$ & 1.53 & 0.03 & 0.29 & 0.01 \\
\hline $\mathrm{Sr}$ & 176.30 & 1.64 & 146.04 & 1.49 \\
\hline $\mathrm{Cd}$ & 0.61 & 0.02 & 0.33 & 0.02 \\
\hline $\mathrm{Ba}$ & 79.15 & 0.81 & 68.55 & 1.04 \\
\hline $\mathrm{Pb}$ & 1.69 & 0.01 & 1.23 & 0.05 \\
\hline $\mathrm{Bi}$ & 0.25 & 0.01 & 0.11 & 0.01 \\
\hline $\mathrm{U}$ & 2.24 & 0.04 & 1.52 & 0.06 \\
\hline
\end{tabular}

Table 2 - Measured concentrations of elements in the two dental calculus samples analysed

Just a few examples for the most relevant elements, taken from literature, are reported in Table 3.

Zinc seems to be an important element in our investigation: its values are higher than those given by Lambert and colleagues for bones belonging to carnivores (Lambert et al., 1984). Zinc is particularly abundant in foods such as red meat, dairy products, nuts, legumes (for example lentils), crustaceans (crabs and shrimps), fish, egg yolk, oats and barley (Allmäe Raili, 2012; Beck, 1985; Busetto et al., 2008; Lambert et al., 1984). This element has the ability to replace calcium in bones, which is, obviously, related to its amount in the diet. Dental calculus is predominantly formed of calcium compounds and its formation depends strongly on diet and oral hygiene. Trace metals are incorporated in bones due to a biological process, whilst in dental calculus a physical inclusion of materials in a growing matrix of calcium phosphates is the predominant process. The two mechanisms are 
deeply different, but the final results both depend on food or other ways of exposition and can be considered as similar.

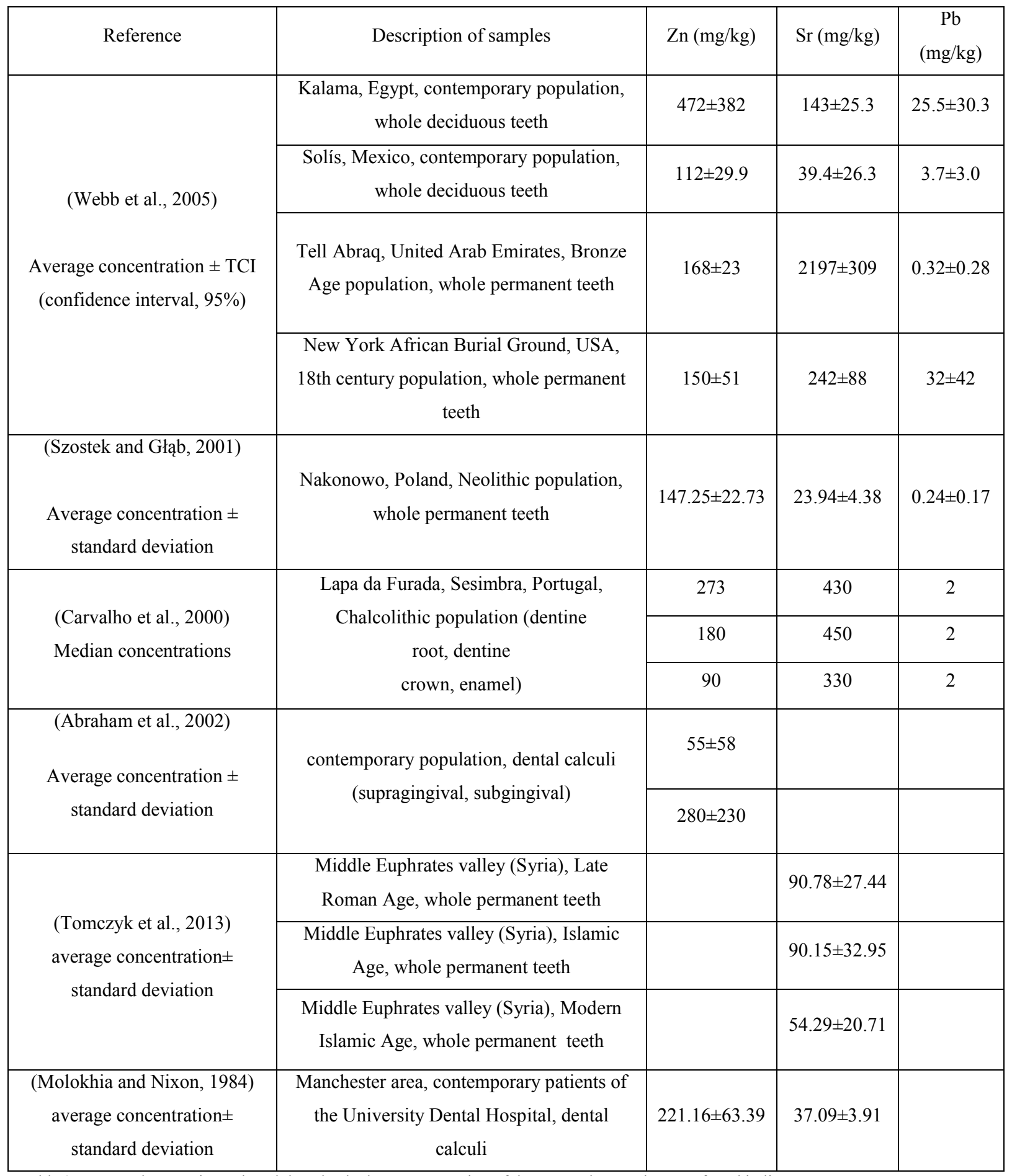

Table 3 - Trace elements in teeth and dental calculus: concentration of the most relevant elements found in literature

Such a high concentration of zinc in our samples could then suggest a relevant intake of proteins, as for what concerns teeth (Szostek and Głąb, 2001; Webb et al., 2005). 
Copper can be found in foodstuffs such as offals, red meat, fish, crustaceans, molluscs, legumes and nuts. The concentrations measured in these samples are compatible with a large consumption of animal proteins (Dobrovolskaya, 2005).

It can also be seen that strontium, a marker of a vegetarian diet, shows concentrations comparable to those tabulated by Lambert and colleagues for carnivores. A reduced consumption of cereals and other vegetables could thus be hypothesised (Lambert et al., 1984). Strontium can also derive from sea fish, shellfish and molluscs, and this evidence becomes particularly relevant when associated with a high level of zinc (Giorgi et al., 2005).

Manganese should be another index of the consumption of vegetables, but the very high values reported in these samples (Tb6 US $115 \quad 334.26 \pm 2.52 \mathrm{mg} / \mathrm{kg}$; Tb7 US $118 \quad 188.18 \pm 2.95 \quad \mathrm{mg} / \mathrm{kg}$ ) cannot be interpreted straightforwardly. It is reported that manganese is particularly abundant in legumes, green vegetables, cereals and nuts (Allmäe Raili, 2012; Aschner and Aschner, 2005). In that epoch, in that region, walnuts and hazelnuts were largely consumed in the diet, and even used to extract oil, so they could be a source of this metal. Another study on the chemical analysis of ancient dental calculus found a high level of manganese in a sample from an Etruscan-Celtic Necropolis (Charlier et al., 2010). In that case, it was attributed to the use of painted ceramic vessels, since the presence of manganese in that kind of pigments is very common. Manganese could also derive from clays used to produce kitchenware or from drinking water.

Lead is used to evaluate post-mortem contamination of the samples: because of its very low concentration values in the analysed calculus, it can be assumed that contamination did not occur. During the Middle-Ages, the use of domestic wares containing this metal, such as glazed vessels, or of drinking water coming from pipelines with lead was common (Allmäe Raili, 2012). However, the low lead levels found indicated that glazed vessels and metal piping was not used for drinking water.

\section{CONCLUSIONS}

This study has shown that the interdisciplinary study of dental calculus from ancient skulls may give important information on diet.

The dissolution of dental calculus and observation of the solid residue showed that phytoliths were mainly derived from Poaceae, Conifers and Dicotyledons (Urticals). In addition to these, it was possible to observe several fragments of burned phytoliths, micro-charcoals, a diatom fragment, fibres, starch granules, and many fragments of quartz, flint and mica.

In this study, few phytoliths, in particular of Poaceae, were observed, which is often the case

(Buchet et al., 2001; Henry et al., 2011; Henry and Pipemo, 2008; Lalueza et al., 1996; Lalueza et al., 1994). This may occur both from the low probability that, after ingestion of fruits and vegetables, such particles remained long enough in the oral cavity to stay trapped inside the calculus during its relatively fast formation, and from the kind and the amount of plant consumption.

Another study (Licata and Pigni, 2012) carried out by some of the authors on the same skulls studied here, examined the wear on the dentition and showed that these teeth have streaks and abrasion typical of people whose diet is based mainly on fish consumption.

Despite the small number of samples that were available for analysis, the ICP-MS showed that trace elements contained in dental calculus exhibited concentrations similar to that in samples taken from skeletons from other 
sites. Furthermore, the concentrations of the various elements matched well with those found in bones and teeth, with the exception of zinc. Its very high concentration could be due to a high consumption of proteins along with plant consumption that is difficult to measure, but that could be partly identified, within the limits of phytolith analysis.

This hypothesis was supported by the location of the town of Caravate, just next to Lake Maggiore, and by the high content of zinc, found by analysis with ICP-MS, which is an index of a protein-based diet.

Fragments of wood and fibres were relatively abundant and larger, and are more typical than fragmentary phytoliths frequently found in many charred food remains within the wall of the vessel of the prehistoric era and later.

In conclusion, it can be hypothesised that the diet of the Medieval inhabitants of Caravate was based on the consumption of both carbohydrates (from plants belonging to the families of Dicotyledons, Monocotyledons such as the Poaceae, also known as Gramineae, and Coniferae) and proteins, mostly coming from fish.

\section{REFERENCES}

Abraham, J., Grenón, M., HSánchez, H.J., Pérez, C., Barrea, R., 2005. A case study of elemental and structural composition of dental calculus during several stages of maturation using SRXRF. Journal of Biomedical Materials Research Part A 75A, 623-628.

Adler, C.J., Dobney, K., Weyrich, L.S., Kaidonis, J., Walker, A.W., Haak, W., Bradshaw, C.J., Townsend, G., Sołtysiak, A., Alt, K.W., 2013. Sequencing ancient calcified dental plaque shows changes in oral microbiota with dietary shifts of the Neolithic and Industrial revolutions. Nature genetics 45, 450-455.

Allmäe Raili, L.-S.J., Heapost Leiu, Verš Evelin, 2012. The content of chemical elements in archaeological human bones as a source of nutrition research. Papers on Anthropology 21 27-49.

Armocida, G., Pozzi, G., 2004. Il nostro paese Caravate. Viganò Grafiche, Sangiano (VA).

Arnay-de-la-Rosa, M., Gonzalez-Reimers, E., Gamez-Mendoza, A., Galindo-Martin, L., 2009. The Ba/Sr ratio, carious lesions, and dental calculus among the population buried in the church La Concepcion (Tenerife, Canary Islands). Journal of Archaeological Science 36, 351-358.

Aschner, J.L., Aschner, M., 2005. Nutritional aspects of manganese homeostasis. Molecular Aspects of Medicine 26, 353-362.

Beck, L.A., 1985. Bivariate analysis of trace elements in bone. Journal of Human Evolution 14, 493-502.

Bentley, R.A., Krause, R., Price, T.D., Kaufmann, B., 2003. Human mobility at the Early Neolithic settlement of Vaihingen, Germany: evidence from strontium isotope analysis. Archaeometry 45, 471-486.

Blatt, S.H., Redmond, B.G., Cassman, V., Sciulli, P.W., 2011. Dirty teeth and ancient trade: Evidence of cotton fibres in human dental calculus from Late Woodland, Ohio. International Journal of Osteoarchaeology 21, 669678. 
Buchet, L., Cremoni, N., Rücker, C., Verdin, P., 2001. Comparison between the distribution of dental microstriations and plant material included in the calculus of human teeth, in: Meunier, J.D., Colin, F. (Eds.), Phytoliths: Applications in Earth Sciences and Human History. CRC Press, pp. 107-117.

Buckley, S., Usai, D., Jakob, T., Radini, A., Hardy, K., 2014. Dental calculus reveals unique insights into food items, cooking and plant processing in prehistoric Central Sudan. PloS one 9, e100808.

Budd, P., Montgomery, J., Cox, A., Krause, P., Barreiro, B., Thomas, R.G., 1998. The distribution of lead within ancient and modern human teeth: Implications for long-term and historical exposure monitoring. Science of the Total Environment 220, 121-136.

Busetto, M., Giordani, L., Brandone, A., Cattaneo, C., Mazzucchi, A., 2008. Dietary investigation by trace element content in bones of ancient inhabitants of Northern Italy, Journal of Radioanalytical and Nuclear Chemistry, pp. 355-363.

Charlier, P., Huynh-Charlier, I., Munoz, O., Billard, M., Brun, L., Lorin de la Grandmaison, G., 2010. The microscopic (optical and SEM) examination of dental calculus deposits (DCD). Potential interest in forensic anthropology of a bio-archaeological method. Legal Medicine 12, 163-171.

Corti, C., Rampazzi, L., Ravedoni, C., Giussani, B., 2013. On the use of trace elements in ancient necropolis studies: Overview and ICP-MS application to the case study of Valdaro site, Italy. Microchemical Journal 110, 614-623.

Djingova, R., Zlateva, B., Kuleff, I., 2004. On the possibilities of inductively coupled plasma mass spectrometry for analysis of archaeological bones for reconstruction of paleodiet. Talanta 63, 785-789.

Dobrovolskaya, M.V., 2005. Upper Palaeolithic and Late Stone Age human diet. Journal of Physiological Anthropology 24, 433-438.

Dudgeon, J.V., Tromp, M., 2012. Diet, geography and drinking water in Polynesia: microfossil research from archaeological human dental calculus, Rapa Nui (Easter Island). International Journal of Osteoarchaeology.

Giorgi, F., Bartoli, F., Iacumin, P., Mallegni, F., 2005. Oligoelements and isotopic geochemistry: a multidisciplinary approach to the reconstruction of the paleodiet. Human Evolution 20, 55-82.

Hardy, K., Buckley, S., Collins, M.J., Estalrrich, A., Brothwell, D., Copeland, L., García-Tabernero, A., GarcíaVargas, S., de la Rasilla, M., Lalueza-Fox, C., Huguet, R., Bastir, M., Santamaría, D., Madella, M., Wilson, J., Cortés, Á.F., Rosas, A., 2012. Neanderthal medics? Evidence for food, cooking, and medicinal plants entrapped in dental calculus. Naturwissenschaften 99, 617-626.

Hayashizaki, J., Ban, S., Nakagaki, H., Okumura, A., Yoshii, S., Robinson, C., 2008. Site specific mineral composition and microstructure of human supra-gingival dental calculus. Archives of oral biology 53, 168-174. 
Henry, A.G., Brooks, A.S., Piperno, D.R., 2011. Microfossils in calculus demonstrate consumption of plants and cooked foods in Neanderthal diets (Shanidar III, Iraq; Spy I and II, Belgium). Proceedings of the National Academy of Sciences of the United States of America 108, 486-491.

Henry, A.G., Pipemo, D.R., 2008. Using plant microfossils from dental calculus to recover human diet: a case study from Tell al-Raqa'i, Syria. Journal of Archaeological Science 35, 1943-1950.

Janos, I., Szathmary, L., Nadas, E., Beni, A., Dinya, Z., Mathe, E., 2011. Evaluation of elemental status of ancient human bone samples from Northeastern Hungary dated to the 10th century AD by XRF. Nuclear Instruments \& Methods in Physics Research Section B-Beam Interactions with Materials and Atoms 269, 25932599.

Klepinger, L.L., 1984. Nutritional assessment from bone. Annual review of anthropology 13, 75-96.

Lalueza, C., Juan, J., Albert, R.M., 1996. Phytolith analysis on dental calculus, enamel surface, and burial soil: information about diet and paleoenvironment. American journal of physical anthropology 101, 101-113.

Lalueza, C., Perezperez, A., Juan, J., 1994. Dietary information through the examination of plant phytoliths on the enamel surface of human dentition. Journal of Archaeological Science 21, 29-34.

Lambert, J.B., Simpson, S.V., Szpunar, C.B., Buikstra, J.E., 1984. Ancient human diet from inorganic analysis of bone. Accounts of chemical research 17, 298-305.

Lambert, J.B., Szpunar, C.B., Buikstra, J.E., 1979. Chemical analysis of excavated human bone from Middle and Late Woodland sites. Archaeometry 21, 115-129.

Licata, M., Pigni, F., 2012. Gli scheletri di Caravate (VA): analisi antropologica e paleonutrizionale di una popolazione alto-medievale., XIII Congresso della Società Italiana di Storia dell'Odontostomatologia, Bologna, Italy.

Lieverse, A.R., 1999. Diet and the aetiology of dental calculus. International Journal of Osteoarchaeology 9 , 219-232.

Lindhe, J., Lang, N.P., Karring, T., 2008. Clinical periodontology and implant dentistry. Fifth edition. WileyBlackwell.

Maurizio, A., 1932. Histoire de l'alimentation vegetale depuis la prehistoire jusqu'a nos jours. Payot, Paris.

Menendez, L.P., Osterrieth, M., Oliva, F., 2009. A first phytolith approximation to diet study in the archaeological site Gascon 1, Pampean Region, Republica Argentina. Quaternary International 204, 84-94.

Mickleburgh, H.L., Pagán-Jiménez, J.R., 2012. New insights into the consumption of maize and other food plants in the pre-Columbian Caribbean from starch grains trapped in human dental calculus. Journal of Archaeological Science 39, 2468-2478. 
Molokhia, A., Nixon, G.S., 1984. Studies on the composition of human dental calculus. Determination of some major and trace elements by Instrumental Neutron Activation Analysis. Journal of Radioanalytical and Nuclear Chemistry 83, 273-281.

Parr, J.F., 2006. Effect of fire on phytolith coloration. Geoarchaeology 21, 171-185.

Perez, C.A., Sanchez, H.J., Barrea, R.A., Grenon, M., Abraham, J., 2004. Microscopic X-ray fluorescence analysis of human dental calculus using synchrotron radiation. Journal of Analytical Atomic Spectrometry 19, 392-397.

Petrocchi, M., 1982. Il simbolismo delle piante in Rabano Mauro e altri studi di storia medievale. Ed. di Storia e Letteratura.

Piperno, D.R., 2006. Phytoliths: a comprehensive guide for archaeologists and paleoecologists. Alta Mira Press.

Power, R.C., Salazar-García, D.C., Wittig, R.M., Henry, A.G., 2014. Assessing use and suitability of scanning electron microscopy in the analysis of microremains in dental calculus. Journal of Archaeological Science.

Price, T.D., Manzanilla, L., Middleton, W.D., 2000. Immigration and the ancient city of Teotihuacan in Mexico: a study using strontium isotope ratios in human bone and teeth. 27, 903-913.

Rheingold, A.L., Hues, S., Cohen, M.N., 1983. Strontium and zinc content in bones as an indication of diet. Journal of Chemical Education 60, 233-234.

Sanchez, H.J., Perez, C.A., Grenon, M., 2000. SRXRF analysis with spatial resolution of dental calculus. Nuclear Instruments and Methods in Physics Research B 170, 211-218.

Schutkowski, H., Herrmann, B., Wiedemann, F., Bocherens, H., Grupe, G., 1999. Diet, status and decomposition at Weingarten: trace element and isotope analyses on Early Mediaeval skeletal material. Journal of Archaeological Science 26, 675-685.

Scott, G.R., Poulson, S.R., 2012. Stable carbon and nitrogen isotopes of human dental calculus: a potentially new non-destructive proxy for paleodietary analysis. Journal of Archaeological Science 39, 1388-1393.

Simonetti, A., Buzon, M.R., Creaser, R.A., 2008. In situ elemental and Sr isotope investigation of human tooth enamel by Laser Ablation-(MC)-ICP-MS: successes and pitfalls. Archaeometry 50, 371-385.

Szostek, K., Glab, H., Szczepanek, A., Kaczanowski, K., 2003. Trace element analysis of Bronze Age skeletal and crematory graves from Southern Poland for diet reconstruction. Homo 53, 235-246.

Szostek, K., Głąb, H., 2001. Trace elements concentrations in human teeth from a Neolithic common grave at Nakonowo (Central Poland). Variability and Evolution 9, 51-59.

Tomczyk, J., Szostek, K., Komarnitki, I., Mankowska-Pliszka, H., Zalewska, M., 2013. Dental caries and chemical analyses in reconstruction of diet, health and hygienic behaviour in the Middle Euphrates valley (Syria). Archives of oral biology 58, 740-751. 
Ungar, P.S., Grine, F.E., Teaford, M.F., El Zaatari, S., 2006. Dental microwear and diets of African early Homo. Journal of Human Evolution 50, 78-95.

Webb, E., Amarasiriwardena, D., Tauch, S., Green, E.F., Jones, J., Goodman, A.H., 2005. Inductively coupled plasma-mass (ICP-MS) and atomic emission spectrometry (ICP-AES): Versatile analytical techniques to identify the archived elemental information in human teeth. Microchemical Journal 81, 201-208.

Wesolowski, V., Ferraz Mendonça de Souza, S.M., Reinhard, K.J., Ceccantini, G., 2010. Evaluating microfossil content of dental calculus from Brazilian sambaquis. Journal of Archaeological Science 37, 1326-1338. 